(C) 1977 IEEE. Personal use of this material is permitted. However, permission to reprint/republish this material

for advertising or promotional purposes or for creating new collective works for resale or redistribution to servers

or lists, or to reuse any copyrighted component of this work in other works must be obtained from the IEEE.

IEEE Transactions on Nuclear Science, Vol.NS-24, No.3, June 1977

\title{
PROGRESS IN SODIUM VAPOR CHARGE EXCHANGE CELL DEVELOPMENT*
}

\author{
H. R. Hiddleston \\ Argonne National Laboratory \\ Argonne, Illinois
}

\section{Introduction}

We have previously reported on efforts of construction and testing of a sodium vapor charge exchange cell. 1 The design utilizes a down jet of sodium from a planar de Laval nozzle impinging upon a liquid sodium pool contained in a condensing reservoir. The apparatus includes provision for return of the sodium to the vaporizing region for replenishing the supply to the jet. The results reported in Ref. 1 were preliminary in that they did not include operation with the full sodium inventory necessary for recirculation.

In this paper, we report the results of measurements made on the cell in the recirculation mode for almost $100 \mathrm{~h}$ of cumulative full temperature operation.

\section{Operation, General}

The operating temperature for the vaporizing region, ducting, and nozzle is $400^{\circ} \mathrm{C}$, while that for the condensing cell is $105-140^{\circ} \mathrm{C}$. The latter temperature is maintained by opposing heating and cooling elements. Approximately $300 \mathrm{~g}$ of sodium was added to the system from an external filling apparatus. Dur ing the four weeks of testing, the entire system was heated up and cooled down many times. The system takes about $2 \mathrm{~h}$ to reach full operating temperature. Cooling is accomplished rapidly by turning off all heaters and increasing the flow of chilled oil to the condensing cell. This also serves to freeze most of the sodium in the reservoir, leaving the ducting and nozzle free.

Between selected tests, the vacuum chamber housing the cell unit was opened by filling with ultrahigh purity nitrogen to a slight positive pressure. Selected flanges were removed to change various test assemblies. Operation after this procedure was verified to return to previous levels.

\section{$\underline{\text { Testing and Results }}$}

The tests performed were of three types: (1) end loss measurements, (2) end loss distribution in the vertical plane, and (3) axial density distribution of the jet. The technique employed was the same for all these; i.e., sodium was collected by freezing on aluminum foils weighed before and after collection, as described in Ref. 1.

The end loss measurements were made in a small chamber on the upstream end of the cell, positioned where the proton source will be. This chamber was isolated from the main cell chamber by a 3 in valve, and provision was made for separate pumping and backfilling of the test chamber. The valve was thus

\footnotetext{
"Work supported by the U. S. Energy Research and
} Development Administration used as a shutter to control the time for exposure of aluminum foil samples to sodium streaming from the end of the cell. The tests were performed with a 2 in disc at a distance from the cell aperture of about 3 in. Times for the tests were typically 15-30 min.

The results are shown in Fig. 1. Total mass collected per unit time is shown versus the cumulative full temperature operation time of the system. The error bars reflect an estimated error in the mass determinations of $0.5 \mathrm{mg}$. The larger errors are due to shorter collection times. The latter few points are averages of several measurements made close together in time. The dashed line indicates the point at which the system was backfilled with nitrogen and opened twice.

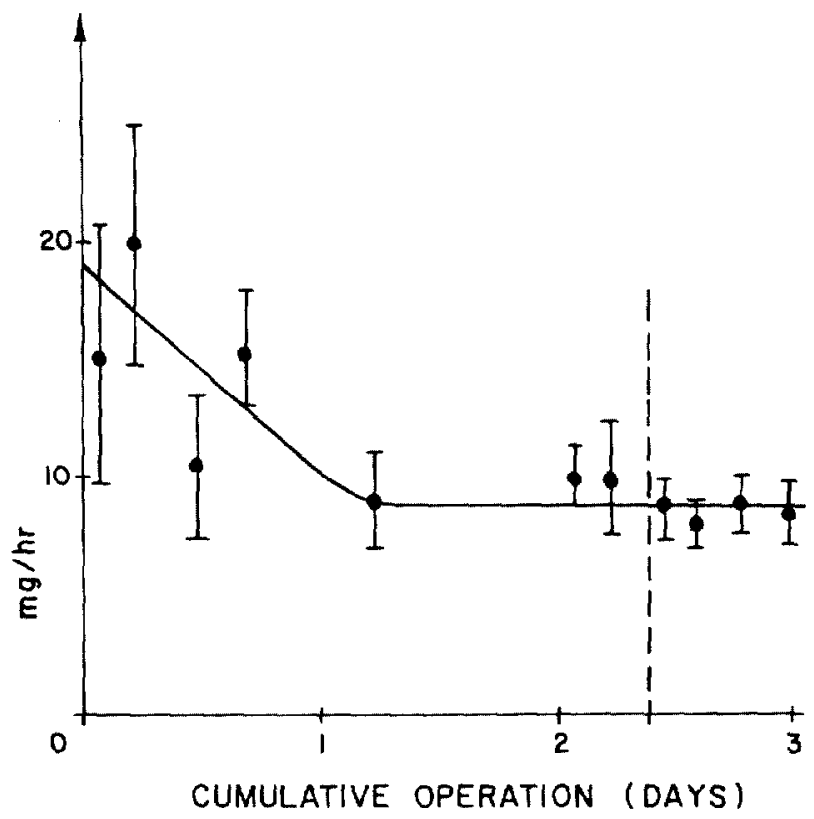

Fig. 1. Sodium deposition on a 2 in disc $\sim 3$ in from one end of the charge exchange cell during operation.

Although the uncertainties are greater for the first few data points, the trend toward decreasing values, levelling off to an average value of $9 \mathrm{mg} / \mathrm{h}$, is evident. This is believed to be indicative of limited circulation and/or surface evaporation effects due to the presence of contaminants in the sodium, notably oxygen as the oxide. This is related directly to the vapor density, and it is not yet known how long this value will be maintained before dropping further.

It was noted that the sodium coating the 2 in disc in the above tests exhibited a pattern considerably thicker at the bottom than at the top. The vertical distribution of the deposited sodium was determined by using $1 / 2$ in aluminum foil squares mounted on a 3 in 
disc at a distance of 6 in from the cell end. Symmetry in the horizontal plane was assumed, and measurements at the same height across the disc were averaged. The results are shown to scale in Fig. 2 . The amount of sodium deposited per unit area per unit time is indicated by the length of the solid bar. It is clear that the vapor streaming from the cell has a definite downward direction. This will aid in keeping sodium from the rest of the system as the major portion of outstreaming material can be collected on liners in the beam tubes. These liners may be cleanable or disposable. The net integrated accumulation on the 3 in disc at 6 in is calculated to be $\sim 2 \mathrm{mg} / \mathrm{h}$ but could be off by a factor of 2 . A measurement of total mass collected for a 2 in disc at 6 in distance gave a result of $6 \mathrm{mg} / \mathrm{h} \pm 2$.

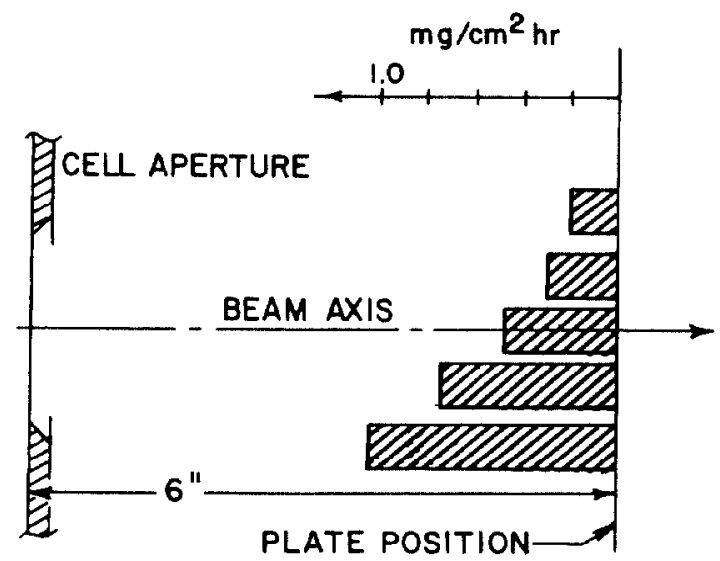

Fig. 2. Vertical distribution of sodium deposited on a 3 in disc at a distance of 6 in from the charge exchange cell during operation.

A third test was performed by means of the multiapertured probe shown in Fig. 8. The inner rod is made of copper and is hollow so that it may be cooled from outside the vacuum by forced air circulation. The outer cylinder is stainless steel with $\sim 1 \mathrm{~cm}^{2}$ apertures spaced at 1 in intervals and distributed symmetrically on each side of the plane of the nozzle. Both inner and outer parts may be turned separately so that the sodium deposited on aluminum foils fixed to the copper rod may be timed. The time used for this test was $2 \mathrm{~min}$.

Results are shown in Fig. 3. The mass deposited was corrected for geometric factors involved, and averages were taken assuming symmetry about the plane of the nozzle. Points are shown at distances along the lines from the nozzle to the foils proportional to the corrected values of mass per unit area per unit time. Error bars reflect the uncertainties in the mass determinations as well as in the averaging procedure.

Calculations of the vapor thickness based on these measurements give values between 0.5 and $1 \times 10^{15}$ atoms $/ \mathrm{cm}^{2}$, which is on the low side of our $1-2 \times 10^{15}$ atoms $/ \mathrm{cm}^{2}$ design value. The mas flow from the

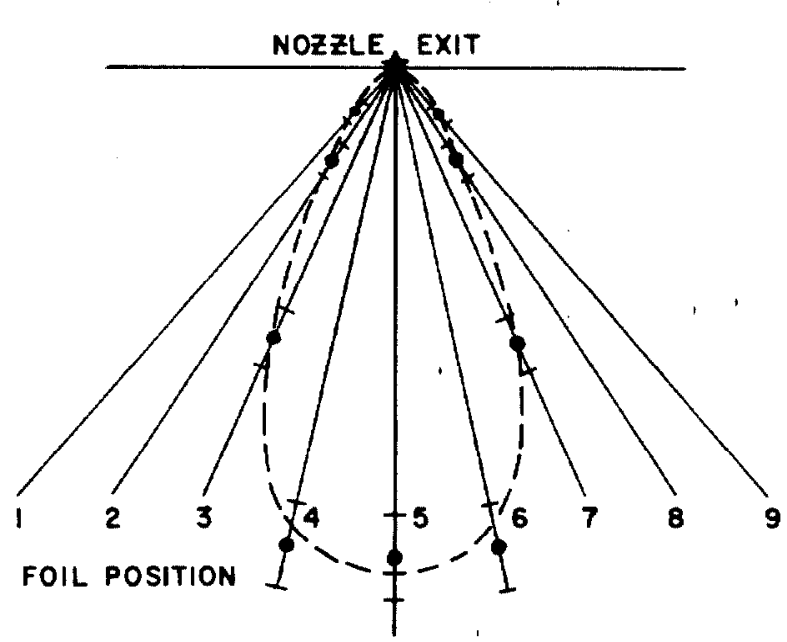

Fig. 3. Relative axial density distribution of sodium from the planar nozzle.

nozzle calculated from these data is $\sim 25 \mathrm{mg} / \mathrm{s}$, which is about half of the theoretical value of $43 \mathrm{mg} / \mathrm{s}$. It is believed that the $9 \mathrm{mg} / \mathrm{h}$ end los $\mathrm{s}$ measurements correspond to a thickness of about $1 \times 10^{15}$ atoms $/ \mathrm{cm}^{2}$ and that the factor of 2 dropoff exhibited in Fig. 1 reflects a drop in the thickness from the design value of $2 \times 10^{15}$ atoms $/ \mathrm{cm}^{2}$.

The entire unit was removed and cleaned, as described in Ref. 1. The double walled stainless tower separating the cell and the nozzle and which had exhibited problems with sodium globules collecting on it has been replaced with a copper tower. (See Fig. 5.) Subsequent operation of the unit has given problems with recirculation possibly due to filling with contaminated sodium, and results are not yet available.

\section{Apparatus}

The various parts and assemblies of the sodium vapor cell unit are shown in Figs. 4-7. The cell and cooling tubing are OFIC copper as are the heater jackets, and all other components are stainless steel. Figure 8 shows the diagnostic probe used for the jet distribution investigation.

\section{Conclusions}

We have demonstrated almost $100 \mathrm{~h}$ of successful operation in the recirculation mode and have met the low side of our design requirements for vapor thickness of $1-2 \times 10^{15}$ atoms $/ \mathrm{cm}^{2}$. Since we would like to minimize the amount of outstreaming sodium, the downward direction of the vapor is encouraging. This will allow us to operate with only a few $\mathrm{mg} / \mathrm{h}$ of sodium getting upstream or downstream more than 6 in from the ends of the cell.

\section{References}

1. H. R. Hiddleston et al., "Sodium Vapor Charge Exchange Cell," Proceedings of the 1976 Proton Linear Accelerator Conference, Chalk River, Ontario, Canada, Report AECL-5677, p. 387 (November 1976). 


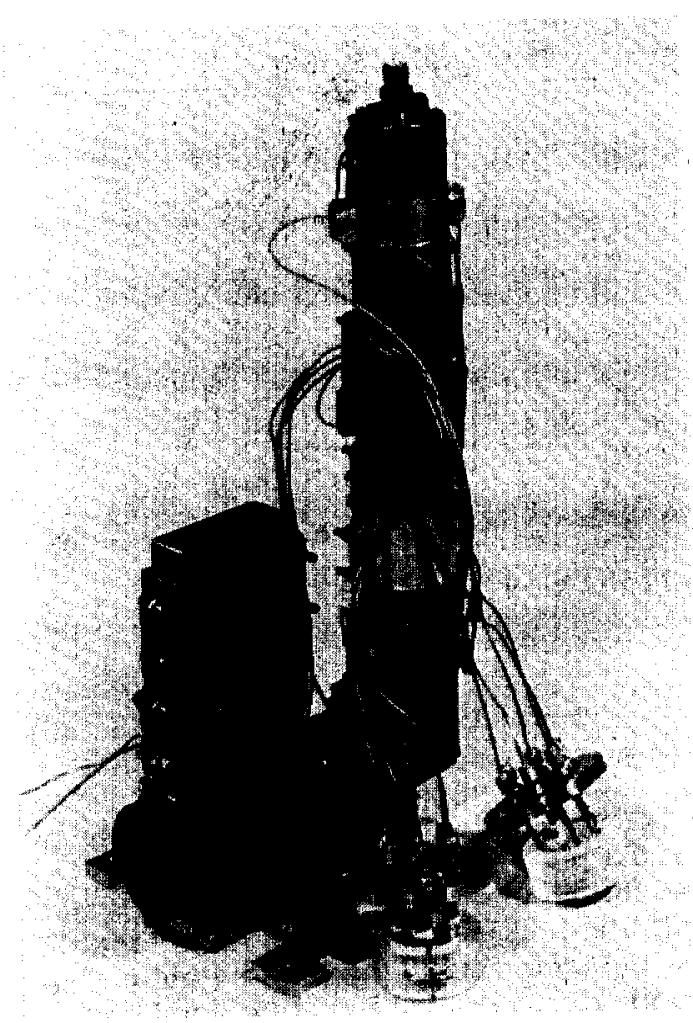

Fig. 4. Sodium vaporizer ducting and planar nozzle showing heater jackets, heaters, and thermocouples clamped in position. Heater and thermocouple feedthrough flanges are also evident.

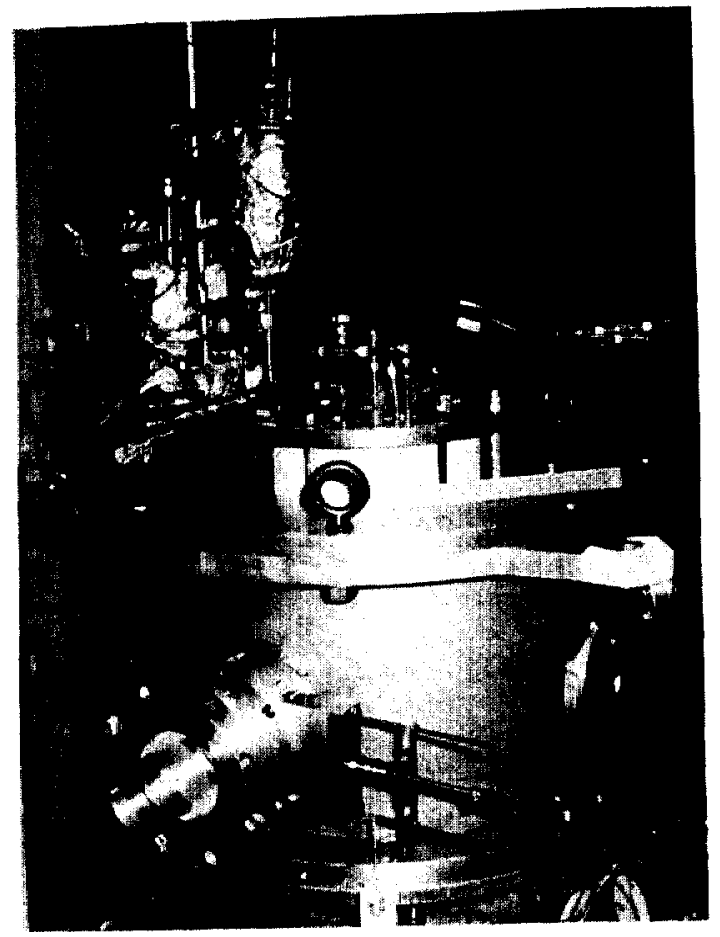

Fig. 7. Sodium vapor cell chamber installation seen from the beam entrance side. The feedthrough plate supporting the cell on its standoff insulator is evident. The test chamber and isolation valve are shown in the foreground. Sodium filling vessels are shown at upper left.

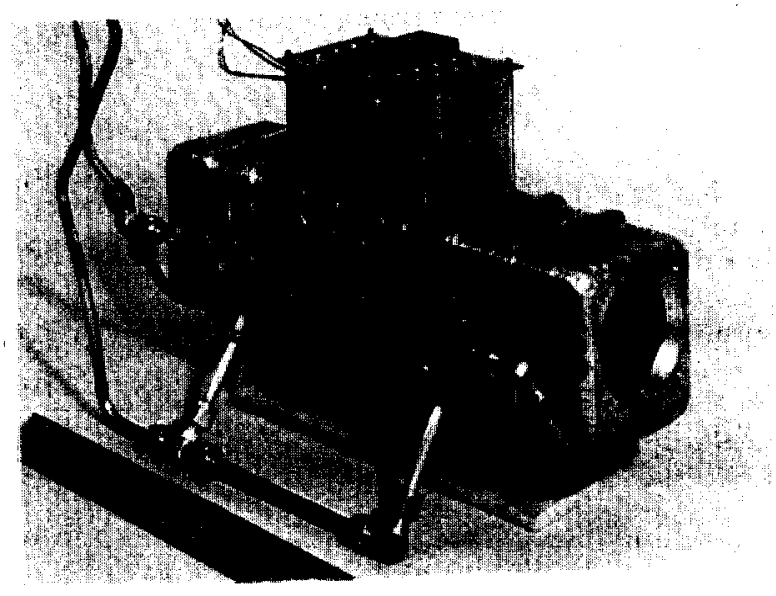

Fig. 5. Sodium condensing cell showing imbedded heaters and cooling tubing.

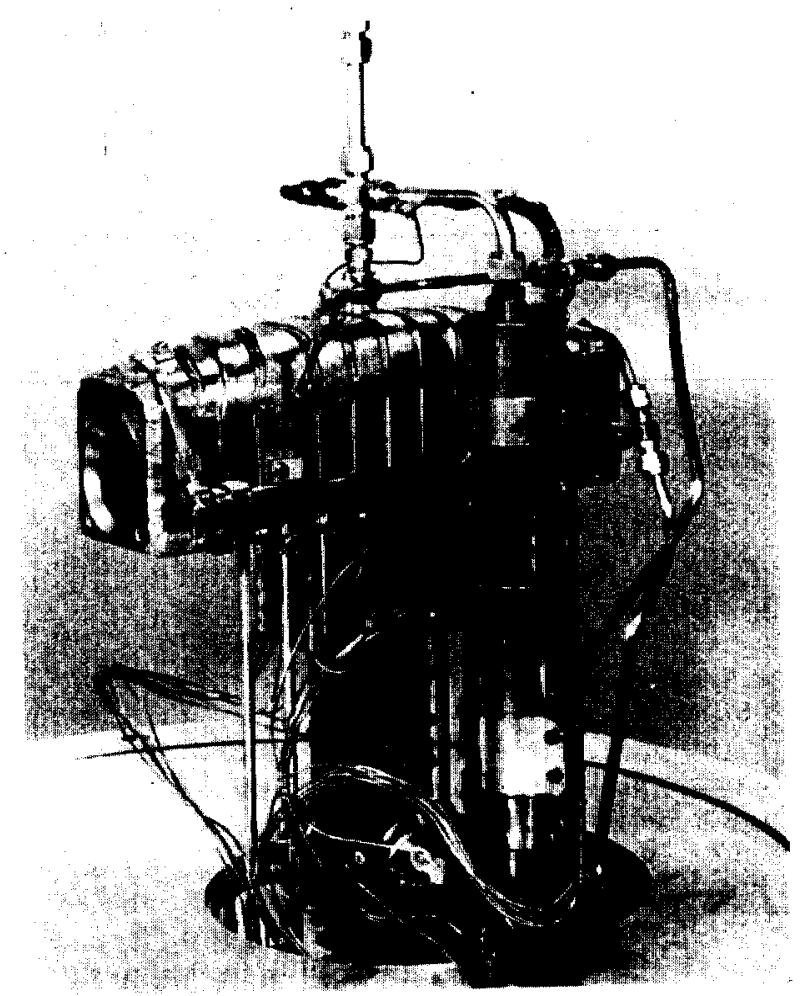

Fig. 6. Assembled sodium vapor cell unit mounted on vacuum chamber lid.

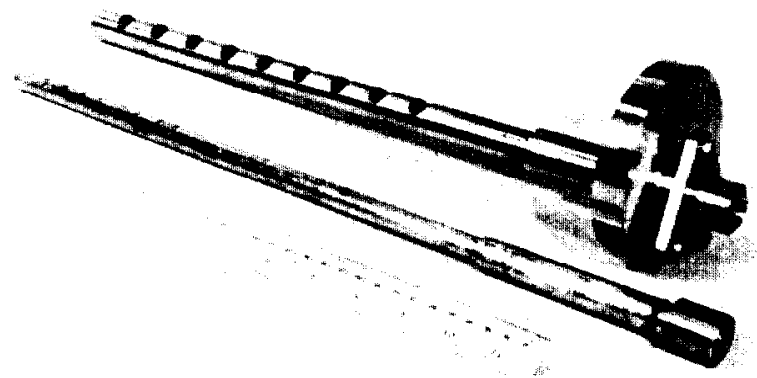

Fig. 8. Probe and multiapertured housing for performing density measurements on the sodium jet. 